\title{
Concepções de alunos da EJA sobre raios e fenômenos relacionados ${ }^{+*}$
}

\author{
Robenil dos Santos Almeidal \\ Welington Cerqueira Júnior ${ }^{2}$ \\ Graduandos em Licenciatura em Física \\ Universidade Federal do Recôncavo da Bahia \\ Eider de Souza Silva ${ }^{3}$ \\ Centro de Formação de Professores \\ Universidade Federal do Recôncavo da Bahia \\ Amargosa - BA
}

\section{Resumo}

O objetivo deste trabalho é identificar e analisar algumas concepções espontâneas sobre fenômenos associados à eletricidade atmosférica, apresentadas por alunos do $2^{\circ}$ ano da Educação de Jovens e Adultos de uma escola pública do interior da Bahia. Os dados foram coletados por meio da aplicação de um questionário e através do processo dialógico durante um minicurso estruturado com base nos Três Momentos Pedagógicos. Os resultados apontaram que determinadas concepções espontâneas são disseminadas pelos familiares dos alunos, através dos mitos passados de geração em geração. Outras, no entanto, são oriundas de interpretações pessoais errôneas sobre os fenômenos elétricos básicos.

Palavras-chave: Fenômenos elétricos; Raios; Concepções espontâneas; Três Momentos Pedagógicos.

\footnotetext{
${ }^{+}$Conceptions of students of EJA about rays and related phenomena

* Recebido: setembro de 2015. Aceito: abril de 2016.

${ }^{1}$ E-mail: robenilww@gmail.com

2 E-mail: welingtoncerqueira@bol.com.br

${ }^{3}$ E-mail: professoreider@yahoo.com.br
} 


\begin{abstract}
The objective of this work is to identify and to analyse some spontaneous conceptions of phenomena associated to the atmospheric electricity, presented by students of $2^{\circ}$ year of Education of Young and Adults (EJA) of a public school in the countryside of Bahia. The data were obtained through a questionnaire and through the dialog process during a minicourse structured with basis in Three Pedagogic Moments. The results pointed out that some spontaneous conceptions are disseminated by the students' relatives through myth passed over generations. Others, however, are originated from erroneous personal interpretations of basic electrical phenomena.
\end{abstract}

Keywords: Electric phenomena; Rays; Spontaneous conceptions; Three Pedagogic Moments.

\title{
I. Introdução
}

Talvez por ser um dos maiores espetáculos da natureza, os raios despertam o interesse de diversos povos desde os primórdios da humanidade. Em seu livro, Pouzadoux (2001) destaca que, na antiguidade, muitos povos associavam as tempestades às divindades; por exemplo, na mitologia grega interpretava-se o raio e o trovão como sinais da ira de Zeus. Ainda hoje, principalmente no Brasil, esse tipo de interpretação existe, como é o caso do culto católico associado à Santa Bárbara (Iansã, pelo sincretismo religioso afro-brasileiro) como senhora dos raios e trovões (BAHIA, 2010).

Apesar desse fenômeno (o raio) ser conhecido desde os tempos mais remotos, foi somente após o desenvolvimento dos estudos sobre eletricidade, no início do século XVIII, que a natureza elétrica da atmosfera terrestre começou a ser desvendada (ASSIS, 2010; ELAT ${ }^{4}$, 2015a; PINTO JR, 2005). Em 1708, William Wall, ao perceber sair faíscas de um pedaço de âmbar carregado eletricamente, notou que o fenômeno lembrava um relâmpago (ASSIS, 2010; HOLTON; RUTHERFORD; WATSON, 1978). Depois, na metade desse mesmo século, foram descobertas outras propriedades elétricas da matéria, evidenciando que os relâmpagos deveriam ser uma forma de eletricidade (ELAT, 2015ª HOLTON; RUTHERFORD; WATSON, 1978).

No entanto, a natureza elétrica dos relâmpagos só foi comprovada por meio de experimentos:

\footnotetext{
${ }^{4}$ A sigla ELAT refere-se ao Grupo de Eletricidade Atmosférica, departamento do Instituto Nacional de Pesquisas Espaciais (INPE) que é responsável pelos estudos dos fenômenos eletromagnéticos que ocorrem na atmosfera terrestre. Seu endereço eletrônico é: <http://www.inpe.br/webelat/homepage/>.
} 
Muitos pensam que foi o filósofo e cientista norte-americano Benjamin Flanklin a primeira pessoa a realizar um experimento em que se observasse fagulhas devidas à eletricidade associada às nuvens. Ele foi precedido pelo pesquisador francês D'Alibard (1752). Um mês depois, em vez de usar uma haste metálica com um fio aterrado como no experimento francês, Benjamin Franklin obteve sucesso empinando um papagaio. Isso permitiu estabelecer cientificamente a presença de eletricidade nas nuvens de tempestade. Franklin sugeriu o uso de condutores para a prevenção da descarga elétrica (MENDES JR; DOMINGUES, 2002, p. 12).

Hoje, sabemos que os relâmpagos são definidos como uma corrente elétrica bastante intensa, com duração aproximada de meio segundo e típica trajetória com comprimento de 5 a 10 km (ELAT, 2015b). Quando o relâmpago acontece entre uma nuvem e o solo ou vice-versa, é chamado de raio (PINTO JR, 2005).

Mesmo com os avanços nos estudos sobre eletricidade atmosférica, ainda assim, os raios parecem provocar uma quantidade significativa de mortes todos os anos. No Brasil, diversos acidentes causados por descargas elétricas atmosféricas foram destaques na mídia entre o final do ano de 2014 e início de 2015, como o caso das quatro pessoas que morreram atingidas por um raio em Praia Grande, $\mathrm{SP}^{5}$, e o acidente ocorrido em Brasília ${ }^{6}$, levando 31 militares da Guarda Presidencial ao hospital por causa de uma descarga elétrica de um raio, entre outros.

Diante do grande número de acidentes causados por raios que são divulgados pela mídia, podemos fazer os seguintes questionamentos:

- Se os fenômenos elétricos já são conhecidos há séculos, por que ainda hoje acontecem muitos acidentes causados por raios?

- Será que as concepções espontâneas das pessoas ajudam a protegê-las dos riscos provenientes dos raios, ou as colocam em situações de perigo?

Por esses e outros questionamentos, buscamos com esta pesquisa identificar e analisar concepções espontâneas de alunos de uma escola pública do interior da Bahia sobre alguns fenômenos associados aos raios.

\section{Metodologia}

Como forma de levar a discussão sobre raios e fenômenos associados para a sala de aula, e também objetivando o levantamento e análise das concepções espontâneas dos alunos

\footnotetext{
5 Disponível em: <http://noticias.uol.com.br/cotidiano/ultimas-noticias/2014/12/29/raio-atinge-orla-de-praiagrande-sp-e-deixa-quatro-mortos.htm>. Acesso em: 7 set. 2015.

${ }^{6}$ Disponível em: <http://g1.globo.com/distrito-federal/noticia/2015/03/queda-de-raio-no-df-leva-31-militares-daguarda-presidencial-ao-hospital.html>. Acesso em: 8 set. 2015.
} 
sobre tais fenômenos, elaboramos um minicurso para estudantes da Educação de Jovens e Adultos (EJA). A escolha da escola e da turma que aplicamos a intervenção se deu a partir da disponibilidade de um docente de física em ceder seus horários para a aplicação da proposta didática.

Utilizamos a metodologia de ensino dos Três Momentos Pedagógicos (3MP), que foram originalmente propostos como desdobramento da educação problematizadora aplicada à construção de um currículo de educação científica (FERRARI, 2008). É importante destacar que a educação problematizadora

[...] é realizada pelo professor com o aluno, e se contrapõe à educação que Paulo Freire chama de "educação bancária", realizada pelo professor sobre o aluno. Para a prática daquela educação é necessário considerar o educando como sujeito da ação educativa, e não como objeto passivo desta, o que implica que a sua participação no processo deve ocorrer em todos os níveis [...] (DELIZOICOV, 1983, p. 85).

Os 3MP, por sua vez, dividem-se em três etapas: problematização inicial, organização do conhecimento e aplicação do conhecimento. É importante destacar que "cada uma das etapas possuem características diferentes que se completam ao longo da atividade ou sequência didática desenvolvida" (CERQUEIRA JR; CERQUEIRA, 2015, p. 57).

Na problematização inicial são apresentadas questões ou situações reais próximas dos alunos, que estejam envolvidas com os conceitos físicos a serem trabalhados nas aulas posteriores. Para que ocorra a problematização inicial, o professor precisa instigar o aluno a expor o que pensa sobre as situações ou questões levantadas (MUENCHEN, 2009). Na nossa intervenção, esta etapa ocorreu quando aplicamos um questionário pré-teste, que possibilitou o levantamento das concepções espontâneas dos estudantes sobre alguns fenômenos relacionados aos raios, e também quando apresentamos o vídeo "Como não ser atingido por raios?" situações de ocorrência do fenômeno, e mais algumas notícias recentes retiradas da internet.

Feita a problematização inicial, devemos nos preocupar com a organização do conhecimento, etapa em que "os conhecimentos de Física necessários para a compreensão do tema central e da problematização inicial serão sistematicamente estudados [...] sob orientação do professor" (DELIZOICOV; ANGOTTI, 1992, p. 29). No nosso minicurso, esta etapa correspondeu ao início apresentação dos conceitos, dividido em duas aulas. Na primeira aula, abordamos alguns conteúdos de eletrostática com utilização de exemplos e experimentos simples. Na segunda aula, foi dada continuidade ao estudo dos conceitos de eletrostática necessários ao entendimento do fenômeno dos raios.

Por fim, na aplicação do conhecimento devemos abordar de forma sistemática os conhecimentos incorporados pelo aluno, com o objetivo de analisar e interpretar a partir dos problemas iniciais e das novas concepções que surgiram por meio da organização do conhecimento (MUENCHEN; DELIZOICOV, 2013). É importante destacar que a aplicação do conhecimento

\footnotetext{
${ }^{7}$ Disponível em: <https://www.youtube.com/watch?v=AyfmurAtpsc\&feature=youtu.be>. Acesso em: 9 set. 2015.
} 
não está limitada a abordar apenas os "problemas locais", e sim, levar a discussão para outros contextos, generalizando as questões levantadas ao longo da problematização para além do cotidiano dos alunos (DELIZOICOV; ANGOTTI, 1992). No nosso minicurso, esta última etapa correspondeu à retomada das questões iniciais dos fenômenos associados aos raios e de outros fenômenos elétricos, mas sendo abordadas agora com os conhecimentos físicos discutidos na organização do conhecimento. Tanto nesta etapa como na organização do conhecimento, foi possível fazer com que os alunos participassem das discussões, expondo suas concepções espontâneas sobre os fenômenos abordados.

Com a utilização da abordagem metodológica dos 3MP, tivemos a possibilidade de promover um processo dialógico ativo em todas as etapas do minicurso, o que garantiu que conseguíssemos obter algumas concepções espontâneas dos alunos sobre fenômenos associados aos raios. É importante destacar que sem a abordagem dialógica, estaríamos limitando a investigação apenas à aplicação do questionário, que, ao nosso ver, não seria tão interessante para um trabalho de levantamento de concepções espontâneas. Assim, com a abordagem dos 3MP, acreditamos que os alunos tiveram mais espaço para expor outras concepções espontâneas não abordadas no questionário.

\section{Resultados}

\section{III.1 Levantamento das concepções espontâneas sobre raios e fenômenos relacionados}

Realizamos a pesquisa com alunos da EJA de uma escola pública estadual da cidade de Amargosa ${ }^{8}$. Participaram desta pesquisa aproximadamente 36 alunos com faixa etária variando entre os 17 e 25 anos, sendo que mais da metade eram do sexo masculino. A turma contava com alunos oriundos tanto da zona urbana quanto da zona rural do município.

Fizemos o levantamento das concepções espontâneas sobre os fenômenos associados aos raios a partir da utilização de um questionário elaborado de acordo com crendices e superstições populares envolvendo tais fenômenos, discutidas no portal do ELAT. No total, elaboramos oito questões.

Para a análise das concepções espontâneas, contabilizamos apenas as respostas dos alunos que participaram da aplicação de toda a intervenção, desde o questionário ao término das aulas. Desta forma, dos 36 alunos que inicialmente faziam parte do minicurso, analisamos as respostas de 27 deles.

Iniciando a análise das respostas do questionário, na primeira pergunta buscamos verificar como os alunos tentavam se proteger dentro de casa durante uma tempestade com incidência de raios. Nesta questão, os alunos deveriam escolher uma alternativa entre as 10 opções

\footnotetext{
${ }^{8}$ Amargosa é uma cidade localizada na região do Centro-Sul da Bahia, no Vale do Jiquiriçá. Atualmente é a sede da 29a Região Administrativa do estado. Disponível em: <http://www1.ufrb.edu.br/cfp/amargosa-cidade-jardim>. Acesso em: 2 set. 2015.
} 
disponíveis. No gráfico da Fig. 1, apresentamos algumas das alternativas mais interessantes para nossa discussão, e a frequência das escolhas.

\section{Qual sua principal forma de proteção contra raios quando está dentro de casa?}

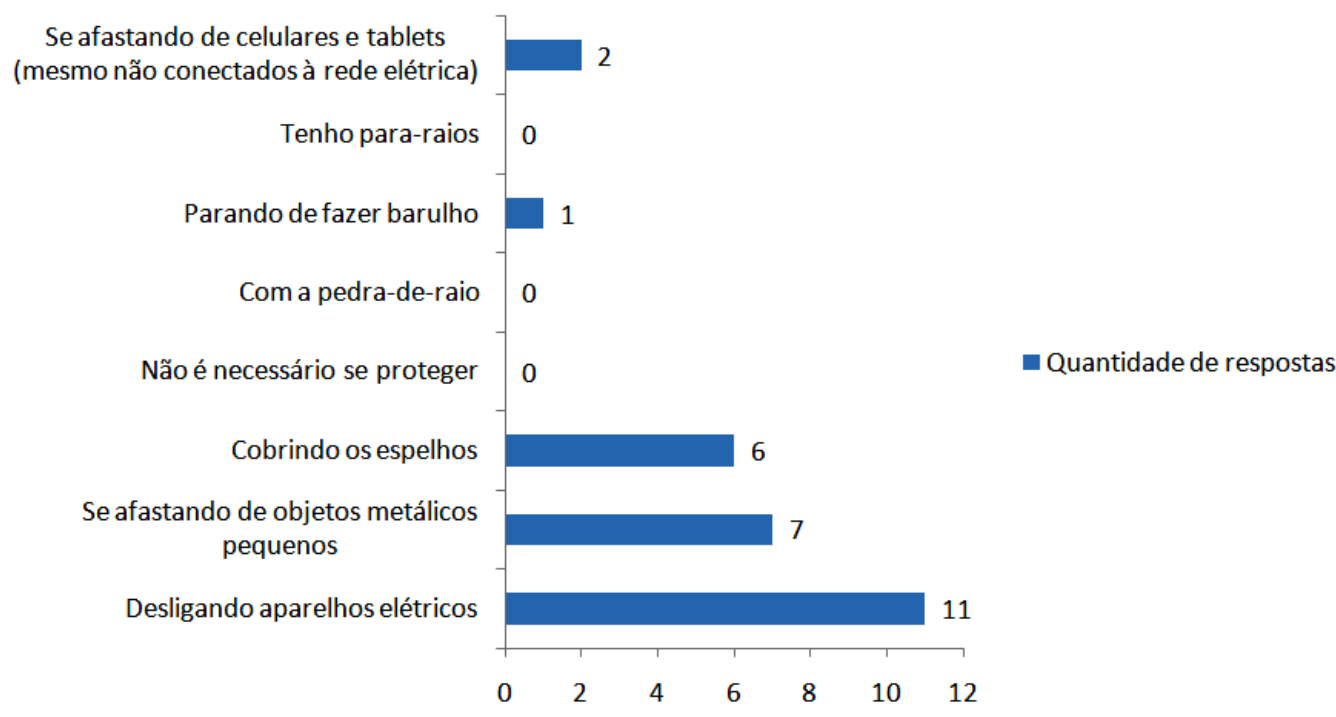

Fig. 1 -Respostas dos alunos à primeira questão.

Analisando esses resultados, notamos que a maioria das respostas (16) está relacionada à mitos e superstições populares sem fundamentação científica, como é o caso de cobrir os espelhos com o intuito de se proteger dos raios, se afastar de objetos metálicos pequenos, aparelhos celulares e tablets (mesmo não conectados à rede elétrica), e até ao ato de fazer silêncio durante uma tempestade.

Por outro lado, não houve nenhuma resposta sobre a utilização da pedra-de-raio (pedra-de-corisco) como amuleto de proteção contra os raios. De acordo com o ELAT (2015c), essa seria uma crença forte no Nordeste, oriunda da influência dos portugueses no século XVI, baseada na falsa explicação de que um local não pode ser atingido mais de uma vez por raios.

No entanto, os resultados aqui obtidos não são suficientes para afirmarmos o enfraquecimento desta crença na localidade pesquisada, já que se trata de uma pesquisa pontual e não foram encontrados indícios de pesquisas semelhantes feitas até então na cidade de Amargosa. Notamos também a partir da primeira questão, que nenhum dos alunos possuía para-raios em suas casas.

Diante das respostas dadas nesta questão, notamos que todos os alunos estavam cientes que, mesmo dentro de casa, é preciso se proteger de alguma forma durante as tempestades. No entanto, o fato do metal ser condutor de eletricidade parece levá-los a acreditar que materiais metálicos, mesmo em pequenas dimensões, podem atrair raios, como foi o caso dos sete alunos que responderam se afastar de objetos metálicos durante as tempestades, o que não é necessário estando dentro de casa (PINTO JR, 2005; YOUNG; FREEDMAN, 2009). 
Na questão seguinte procuramos investigar o motivo pelo qual alguns dos alunos pesquisados cobriam espelhos durante as tempestades. Apresentamos os resultados no gráfico da Fig. 2.

\section{Espelho atrai raios?}

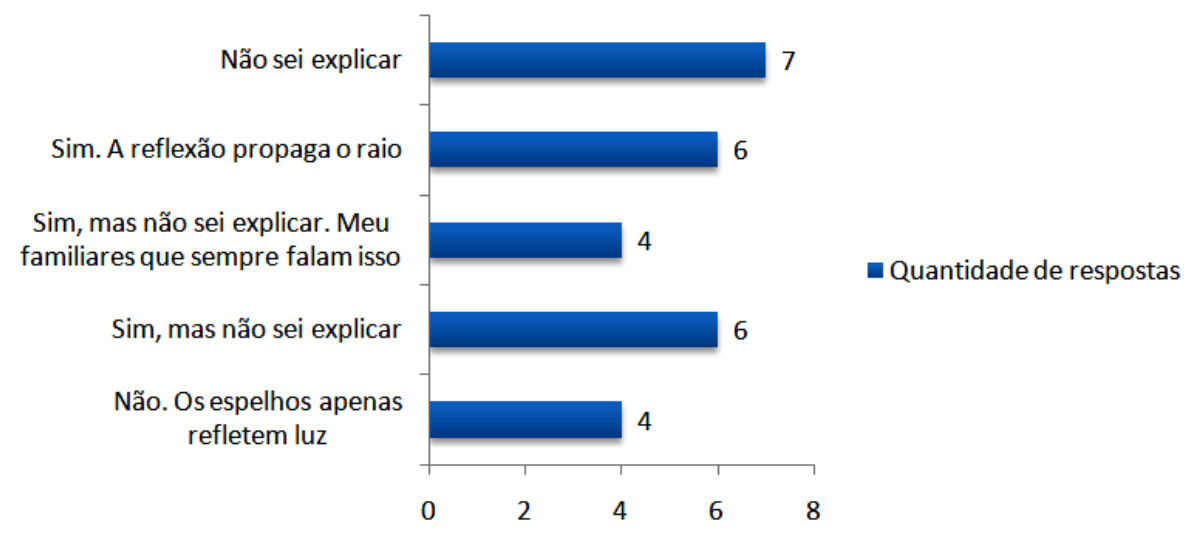

Fig. 2 - Resultados da questão 2.

Analisando a questão, percebemos a quantidade de respostas que apontam para o fato dos alunos acreditarem que os raios podem ser atraídos por espelhos "descobertos": ao todo dezesseis respostas, sendo que seis alunos não souberam justificar a causa da "atração", quatro afirmaram cobrir os espelhos por influência dos familiares (principalmente pais e avós), e seis justificaram a resposta afirmando os espelhos como objetos com propriedades de atração e reflexão de raios. Para estes últimos, a palavra "refletir" pareceu ser sinônimo de "transmitir".

A crença de cobrir espelhos é muito antiga. Surgiu na época em que os espelhos eram confeccionados com grandes molduras metálicas, nesse caso apenas, o objeto seria um grande atrativo para os raios (ELAT, 2015c).

Das respostas que não foram afirmativas, apenas quatro alunos responderam não acreditar na "propriedade de atração de raios por espelhos", justificando que "refletir não significa transmitir", e sete não souberam responder a questão.

Com a terceira questão, buscamos identificar do que os alunos tinham mais medo durante uma tempestade. Apesar de termos orientado para a escolha de apenas uma alternativa, alguns alunos escolheram mais de uma opção. Com isso, obtivemos trinta e quatro respostas e optamos por anular os questionários com múltiplas escolhas. Assim, foram analisados apenas vinte questionários, os dados estão apresentados na Fig. 3. 


\section{Do que você mais tem medo numa \\ tempestade?}

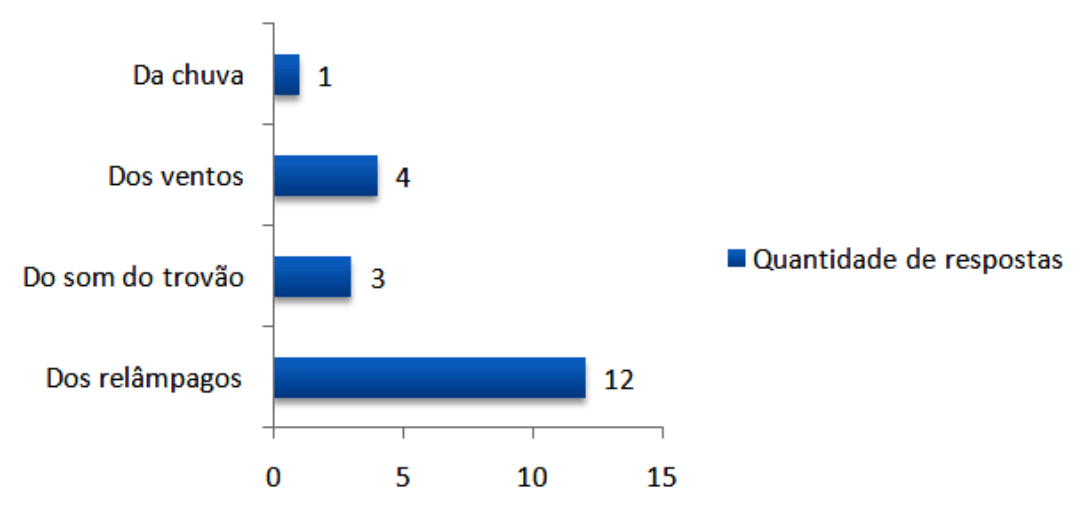

Fig. 3 - Resultados da questão 3.

No geral, a maioria dos alunos afirmou ter medo dos relâmpagos. O restante das respostas dividiu-se entre ventos (quatro respostas), trovões (três) e chuva (uma).

Na questão 4 , tivemos o objetivo de verificar quais justificativas os alunos dariam na tentativa de explicar o motivo pelo qual, durante um relâmpago, vemos primeiro o clarão para depois ouvirmos o som do trovão. Havia um texto base ${ }^{9}$ definindo como se formavam o clarão e o trovão, e em seguida perguntávamos: "O trovão e o clarão são resultados de um mesmo fenômeno, o relâmpago. Por qual motivo então vemos primeiro o clarão para depois ouvir o som do trovão?".

De acordo com o que foi identificado na nossa análise, nenhum dos alunos conseguiu responder de maneira satisfatória a questão. Mesmo sendo especificado que o clarão e o trovão fazem parte do relâmpago, pelo que notamos, os alunos ainda assim os consideravam como eventos distintos. Tal suspeita se evidenciou durante as aulas seguintes, através das falas de alguns alunos. Essa confusão conceitual possivelmente dificultou a compreensão da questão por parte dos estudantes.

Dando continuidade à análise das questões, na Fig. 4 apresentamos os resultados da quinta questão, que foi elaborada com intuito de investigar se os alunos sabiam qual era a principal causa da grande incidência de raios no Brasil.

A resposta correta para esta questão é o clima tropical, pois o Brasil possui a maior área com clima tropical do planeta (PINTO JR, 2005). Nas regiões tropicais, o clima é mais quente, favorecendo a formação de tempestades e de raios (ELAT, 2015d).

A grande extensão territorial como fator de influência para a alta incidência de raios no Brasil também é uma resposta razoável. Porém, na questão cobramos que cada aluno iden-

\footnotetext{
${ }^{9} \mathrm{O}$ texto base foi elaborado de acordo com um texto do ELAT. Disponível em: <http://www.inpe.br/webelat/homepage/menu/relamp/relampagos/definicao.php>. Acesso: 1 set. 2015.
} 
tificasse o “principal responsável pela grande incidência de raios no Brasil”. Já a resposta referente a proximidade com o litoral é equivocada, pois as maiores incidências de raios no território brasileiro não estão necessariamente em regiões litorâneas (ELAT, 2015e).

\section{Por que o Brasil é o país com maior incidência de raios no mundo?}

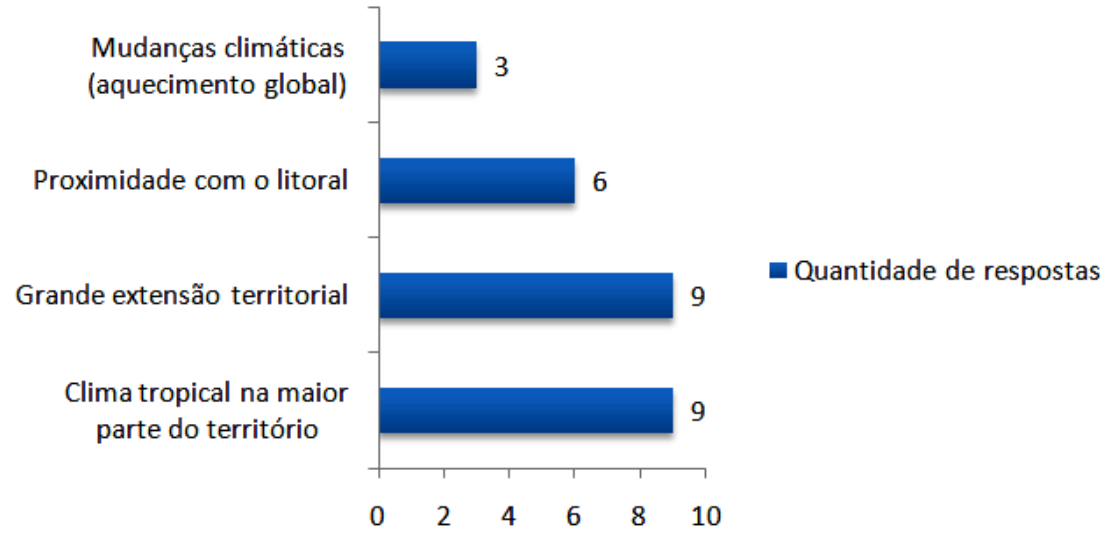

Fig. 4 - Resultados da questão 5.

As mudanças climáticas, principalmente decorrentes da urbanização, podem sim influenciar o aumento na ocorrência das tempestades em determinadas regiões (FEITOSA, 2010), o que está de acordo com a afirmação de três alunos. No entanto, na questão perguntamos sobre o fator responsável pela grande incidência de raios no Brasil e não sobre o aumento das ocorrências de tempestades.

Na sexta questão, apresentamos uma situação onde o aluno deveria se imaginar nela para poder responder: "[...] você está num local descampado, onde existe apenas uma árvore [...]. Em seguida, começa uma tempestade com muitos raios e você não tem chances de sair do local com segurança. O que você faria para se proteger e não ser atingido por um raio nesse local?".

Fornecemos as seguintes alternativas:

I- ficaria distante da árvore e agacharia pondo as mãos nos joelhos e a cabeça entre eles, pois não estando em pé e nem em contato direto com o chão, os riscos de ser atingido por um raio tornam-se reduzidos;

II- ficaria em pé bem distante da árvore, porque ela atrai raios;

III- ficaria longe da árvore e deitaria no chão até a tempestade passar, pois os raios incidem mais facilmente em pontos altos;

IV- não ficaria embaixo da árvore, mas próximo dela, pois qualquer raio "cairia" somente na árvore, porque ela seria o ponto mais alto do local, e

V-ficaria embaixo da árvore, caso tivesse "caído" algum raio nela, pois um raio não cai duas vezes no mesmo lugar. 
As respostas obtidas são apresentadas no gráfico da Fig. 5.

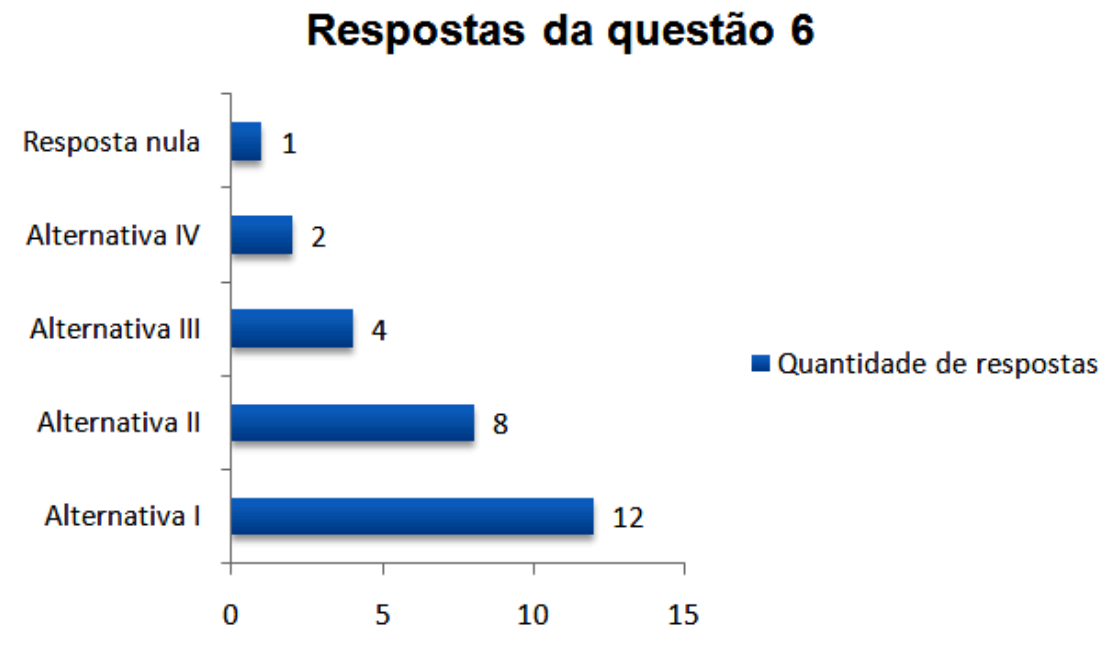

Fig. 5 - Respostas obtidas na sexta questão.

Do total de respostas, doze alunos se comportariam corretamente, ficando agachados com a cabeça entre os joelhos e distante da árvore isolada (PINTO JR, 2005; SABA, 2001). As outras respostas, que representam maneiras perigosas de se proteger de raios em local descampado, foram: oito ficariam em pé, mas bem distante da árvore (risco grande, pois os raios geralmente incidem sobre estruturas altas), quatro ficariam longe da árvore e deitariam no chão (risco de sofrer descargas "subterrâneas" caso algum raio incida no local, pois a terra é um condutor de eletricidade), e dois afirmaram que ficariam próximos da árvore porque ela seria o ponto mais alto do local (risco de sofrer descargas laterais) (GASPAR, 2013; HALLIDAY; RESNICK; WALKER, 2009; NUSSENZVEIG, 2002; PINTO JR, 2005; SABA, 2001).

Percebemos que mais da metade dos alunos questionados não se comportariam corretamente no intuito de preservar as suas vidas, representando um grande risco para eles próprios em situações desse tipo. Esta observação nos leva a considerar determinadas concepções espontâneas como "perigosas", pois elas podem contribuir para o acontecimento de acidentes ocasionados por raios.

Um ponto importante a ser destacado é que a alternativa "ficaria embaixo da árvore, caso tivesse 'caído' algum raio nela, pois um raio não cai duas vezes no mesmo lugar" não foi escolhida por nenhum aluno. Como aplicamos esta pesquisa localmente, não é possível fazermos generalizações, ficando difícil assumir que o mito "um raio não cai duas vezes no mesmo lugar" vem deixando de existir na região pesquisada. Esta crença é um dito popular muito comum, mas é apenas um mito (PINTO JR, 2005; SABA, 2001). Em áreas de grande incidência podem cair raios várias vezes no mesmo local, como é o caso do Cristo Redentor, cartão postal da cidade do Rio de Janeiro, que é atingido em média seis vezes por ano ${ }^{10}$.

\footnotetext{
10 Disponível em: <http://noticias.uol.com.br/ciencia/ultimas-noticias/redacao/2014/11/25/clique-ciencia-raioscaem-duas-vezes-em-um-mesmo-lugar.htm>. Acesso: 2 set. 2015.
} 
Prosseguindo com a análise do questionário, na questão 7 apresentamos vários conceitos que os alunos deveriam classificar como verdadeiro ou falso. Nesta questão, obtivemos as seguintes repostas, apresentadas na Tabela 1.

Tabela 1 - Resultados de cada item da questão 7.

\begin{tabular}{|l|c|}
\hline \multicolumn{1}{|c|}{ Item } & $\begin{array}{c}\text { Resultados/ Quant. } \\
\text { de respostas }\end{array}$ \\
\hline $\begin{array}{l}\text { a) Um relâmpago pode acontecer entre uma nuvem e a terra, entre } \\
\text { nuvens, no interior de uma nuvem ou entre a terra e a nuvem (raio } \\
\text { ascendente). }\end{array}$ & $\begin{array}{c}\text { Verdadeiro: } 11 \\
\text { Falso: } 16\end{array}$ \\
\hline $\begin{array}{l}\text { b) Qualquer objeto metálico pode atrair raios. Por exemplo, um } \\
\text { prego. }\end{array}$ & $\begin{array}{c}\text { Verdadeiro: } 21 \\
\text { Falso: } 6\end{array}$ \\
\hline $\begin{array}{l}\text { c) Ficar no rio, lagoa ou mar é extremamente perigoso numa tempes- } \\
\text { tade. }\end{array}$ & $\begin{array}{c}\text { Verdadeiro: } 24 \\
\text { Falso: } 3\end{array}$ \\
\hline d) Estruturas altas, como torres e postes, podem atrair raios. & $\begin{array}{c}\text { Verdadeiro: } 22 \\
\text { Falso: } 5\end{array}$ \\
\hline e) Só "caem" raios se estiver chovendo. & $\begin{array}{c}\text { Verdadeiro: } 11 \\
\text { Falso: } 16\end{array}$ \\
\hline
\end{tabular}

Fonte: Elaborada pelos autores

De modo geral, a partir dos dados da Tabela 1, podemos chegar a algumas conclusões. O resultado obtido no item "a" representa bem a concepção popular de que os raios "caem". Esse tipo de crença também foi encontrado em outras pesquisas da área. Medeiros A. e Medeiros C. (2002) relatam que a imagem arquetípica sobre os raios no imaginário popular é algo que cai: "o raio cai nos postes"; "o raio cai nos lugares mais altos"; entre outros.

Esta crença também é reforçada pela dificuldade que as pessoas em geral possuem em visualizar a ocorrência dos raios ascendentes, pois, "o raio ascendente é raro e só acontece a partir de estruturas altas no chão (arranha-céus) ou no topo de montanhas (torres, antenas)" (SABA, 2001, p.20).

No item "b", a maioria dos estudantes afirmou ser verdade que qualquer objeto metálico pequeno como, por exemplo, um prego, pode atrair raios. Por meio do resultado, notamos que os alunos pareceram confundir condução elétrica com força eletrostática, que está diretamente relacionada à atração ou repulsão de cargas elétricas (NUSSENZVEIG, 2002). No entanto, "os condutores são materiais nos quais as cargas elétricas se movem com facilidade, como os metais (como o cobre dos fios elétricos), o corpo humano e água da torneira" (HALLIDAY; RESNICK; WALKER, p. 3). Esta concepção também esteve presente na questão 1, quando 7 dos pesquisados afirmaram se afastar de objetos metálicos com pequenas dimensões durante uma tempestade, mesmo estando dentro de casa.

Os resultados dos itens "c" e "d" aparentemente nos mostram que a maioria dos alunos possuía conhecimento dos riscos que é estar em praias, rios, lagos e próximo de estruturas altas 
durante tempestades. Apesar de que a "atração" de raios por estruturas altas seja considerada como uma concepção espontânea, ela é importante, pois,

Embora, em termos científicos, não haja propriamente uma atração, mas uma tendência das descargas se efetuarem entre as nuvens e a Terra nos locais mais altos e pontiagudos, devido ao poder das pontas (consequência da Lei de Gauss), a aparência de atração é realmente cativante. Em termos de precauções a serem tomadas, lugares a serem evitados em dias de tempestades, entretanto, deve ser ressaltado que esse tipo de crença popular tem um efeito bastante positivo como medida cautelar de proteção (MEDEIROS A.; MEDEIROS, C., 2002, p. 92).

No item "e", o resultado obtido mostra mais da metade dos pesquisados considerando a afirmação de que só acontece incidência de raios se estiver chovendo como falsa (o que condiz com a realidade), enquanto o restante respondeu ser verdadeira a ocorrência desse evento apenas com chuva. Alguns referenciais ${ }^{11}$ disponíveis na internet, até mesmo de fontes governamentais, explicam de maneira fisicamente incorreta o fenômeno da incidência de "raios sem chuva". A explicação mais presente nesses referenciais diz que "os raios podem chegar ao solo a até $15 \mathrm{~km}$ de distância do local da chuva", quando, na verdade, a justificativa fisicamente correta é que os relâmpagos se formam da quebra da rigidez dielétrica do ar, que ocorre quando o campo elétrico da nuvem de tempestade é muito intenso, capaz de ionizar os átomos do ar, acelerando os elétrons a produzir a descarga elétrica (PINTO JR, 2005). Portanto, não é a distância de um local até onde esteja ocorrendo uma tempestade a justificativa para os "raios sem chuva", e sim a quebra da rigidez dielétrica do ar, provocada por uma diferença de potencial muito grande, independentemente de estar chovendo ou não (GASPAR, 2013; NUSSENZVEIG, 2002).

Por fim, chegamos a análise da questão 8, em que procuramos verificar se os alunos já presenciaram de perto a ocorrência de um raio.

A partir dos resultados apresentados na Fig. 7, notamos que a maioria dos alunos respondeu nunca ter visto um raio "cair" perto do local onde se encontrava num dia de tempestade. Apenas quatro alunos afirmaram terem visto o fenômeno de perto, como descreveu um deles: "No quintal da casa dos meus avôs, durante uma chuva muito forte e com raios, ele caiu no quintal, em uma árvore".

\footnotetext{
${ }^{11}$ Algumas referências encontradas na internet que explicam desta forma: $<$ http://www.marica.rj.gov.br/defesa/ raios.php>; <http://www.cbm.mt.gov.br/?f=pagdinamica1 \&id=63>; <http://www.tvsuperativa.com.br/ 2015/02/ descarga-de-raio-atinge-adolescente-em-santa-cruz-das-palmeiras-sp/>, entre outras.
} 


\section{Você já viu um raio de perto?}

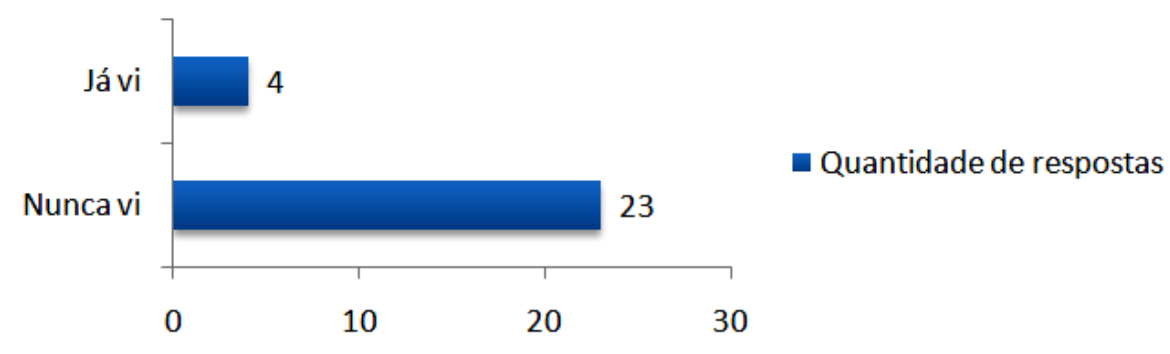

Fig. 7 - Resultados da questão 8.

Por ser a última questão, somado ao fato do questionário ter sido aplicado no último horário de aula (cada horário de aula corresponde a 50 minutos), e uma parte significativa dos alunos dependia do transporte público para retornar as suas casas, isso pode justificar o grande número de respostas negativas dadas a esta questão, pois esse resultado foi contraditório com o que os alunos expuseram durante o processo dialógico. Além desta contradição, outras concepções espontâneas também foram aparecendo no decorrer de todas as etapas dos 3MP, que descreveremos a seguir.

\section{III.2 Concepções espontâneas identificadas através do processo dialógico}

Após a aplicação do questionário de conhecimentos prévios, iniciamos a fase de intervenção didática, correspondendo ao desenvolvimento do minicurso "Como não ser atingido por raios?". Tanto a aplicação do questionário quanto a fase inicial do minicurso, corresponderam a problematização inicial.

O primeiro momento do minicurso foi iniciado com a exibição do vídeo, cujo título é o mesmo do minicurso, que mostrava vários incidentes e situações envolvendo raios. A utilização do recurso audiovisual foi importante para instigar nos alunos o interesse para os temas que seriam abordados a partir do estudo dos fenômenos associados à eletricidade atmosférica. Assim, foi possível obter outras concepções espontâneas a partir do diálogo entre alunos e professores. Nesta seção, também descreveremos concepções espontâneas dos alunos sobre alguns fenômenos da eletrostática em geral.

Em seguida, fizemos uma experiência com os alunos. Distribuímos pequenos pedaços de papel, e pedimos para que cada estudante esfregasse uma caneta no cabelo e em seguida aproximasse a caneta dos pedaços de papel. Apesar da experiência ser relativamente simples e bastante divulgada, alguns alunos questionaram com muita curiosidade o motivo pelo qual a caneta atraía os pedacinhos de papel, e outros afirmaram que nunca viram ou tinham feito isso. Além disso, alguns alunos não conseguiram realizar a atividade, pois notamos que estes estavam com o cabelo úmido, facilitando a dissipação do excesso de cargas acumuladas na caneta (NUSSENZVEIG, 2002). 
O fato da experiência não ter funcionado para alguns alunos, pareceu ter aguçando ainda mais a curiosidade dos demais, pois tivemos uma participação além do esperado, com muitas hipóteses sendo levantadas. Inicialmente não explicamos o ocorrido na experiência, pois demos tempo para os alunos pensarem à respeito dos fenômenos que estavam envolvidos e tentassem dar suas explicações.

Após a exibição do vídeo e da realização da experiência, iniciamos uma aula expositiva dialogada, em que apresentamos os conceitos básicos de eletrostática, dentre eles, o início dos estudos sobre eletricidade, o modelo clássico do átomo, as propriedades básicas das cargas elétricas, os processos de eletrização, condutividade elétrica e o "poder das pontas". Antes dos conceitos iniciais sobre eletrostática, fizemos algumas perguntas aos alunos ${ }^{12}$ :

P1: Vocês sabem que fenômeno é esse que faz a caneta atrair os pedaços de papel após atritá-la?

A11: Acho que é eletricidade estática.

P1: Alguém mais acha que é eletricidade estática também?

(Silêncio na sala)

P1: Pessoal, por que a caneta está atraindo os papéis?

A3: Ao atritar a caneta no cabelo, ela esquenta e daí acontece a atração dos pedacinhos de papel.

P2: Sua resposta é razoável, mas não é esse fenômeno o responsável pela atração exercida pela caneta sobre os pedaços de papel. Vamos responder essa questão mais adiante, primeiro é necessário que vocês compreendam alguns outros conceitos.

Quando apresentamos sobre a descoberta da eletricidade e algumas propriedades das cargas elétricas, ficou evidente a dificuldade de muitos alunos para compreender alguns fenômenos que envolvem esses conceitos:

A1: Professor, se eu atritasse o âmbar com lã, sairia fogo?

P2: Não. O que aconteceria seria o âmbar adquirir a propriedade de atrair pequenos objetos, como penas de aves. É o mesmo fenômeno que aconteceu quando atritamos a caneta no cabelo e a aproximamos dos pedacinhos de papel.

O fato de um corpo eletricamente neutro possuir carga elétrica nula - número de prótons (carga positiva) igual ao número de elétrons (carga negativa) - gerou também uma confusão conceitual para alguns alunos. A principal "confusão" deu-se pelo fato do termo "carga elétrica nula" ter sido confundido com "inexistência de elétrons e prótons na matéria". Constatamos isso por meio de perguntas feitas em sala.

\footnotetext{
12 Os alunos estão sendo referenciados como "A" seguido de um número. Já os professores do minicurso estão mencionados como P1 e P2.
} 
Em seguida, discutimos os conceitos de quantização de carga, condutividade elétrica, processos de eletrização e "poder das pontas". Durante a explicação desses conceitos, aconteceram alguns outros questionamentos por parte dos alunos, mas que não se mostram relevantes ao propósito deste trabalho, por isso, não serão citados.

Após o término da primeira parte do minicurso, realizamos a aplicação do conhecimento, cujo objetivo foi o estudo dos fenômenos associados aos raios a partir do que foi discutido na aula anterior. Iniciamos com uma breve abordagem histórica dos estudos dos fenômenos elétricos atmosféricos desde a antiguidade até os dias atuais. Em seguida, explicamos o processo de formação de raios, quando um dos alunos expôs uma dúvida:

A12: Professor, por que o raio vem antes do trovão?

P1: Se vocês recordarem, essa foi uma das perguntas do questionário que fizemos antes do minicurso. Alguém de vocês conseguiu responder?

A4: Eu mesmo não consegui responder!

P2: O que se propaga mais rápido, o som ou a luz?

A2, A4 e A13: A luz!

P1: Quem acha que é o som, levanta a mão. Agora, que acha que é a luz, levanta a mão.

\section{P1: Luz ganhou!}

P2: Muito bem, quem respondeu "luz". A luz se propaga no vácuo a uma velocidade de, aproximadamente, $3,0 \times 10^{8}$ metros por segundo, enquanto que o som se propaga em média a 340 metros por segundo! A velocidade da luz é absurdamente muito maior que a do som, e por esse motivo, durante um relâmpago, observamos primeiro o clarão e só depois de um tempo que ouvimos o som do trovão. Quanto maior for a nossa distância do local onde aconteceu o relâmpago, demoraremos ainda mais tempo para escutar o som do trovão.

Complementando essa discussão, muitos dos alunos disseram achar que a causa do trovão era devido ao "choque" entre as nuvens. É importante destacar que essa é uma concepção espontânea bastante comum:

Muita gente acha que o trovão é o barulho causado pelo choque entre nuvens. Esta ideia é errada e muito antiga. Lucrécio (98-55 a.C.) acreditava que tanto o raio como o trovão eram produzidos por colisões entre nuvens. Na verdade é o rápido aquecimento do ar pela corrente elétrica do raio que produz o trovão. Assim como uma corrente elétrica aquece a resistência de nossos aquecedores, a corrente do raio, ao passar pelo ar (que é um péssimo condutor), aquece-o e ele se expande com violência, produzindo um som intenso e grave (SABA, 2001, p. 21).

Posteriormente, outro aluno realizou alguns questionamentos importantes: 
A22: Um raio é uma descarga elétrica sempre positiva?

P1: Depende. Ele pode ser uma descarga tanto positiva quanto negativa. Tudo vai depender da distribuição de cargas no interior da nuvem de tempestade e da indução de cargas que foi gerada na terra.

A22: Entendi. Outra dúvida: o para-raios espalha o raio?

P1: É bem por esse caminho. De maneira simplificada, podemos afirmar que o pararaios funciona como uma espécie de fio-terra.

Um ponto interessante a ser mencionado é que, antecedendo a essa segunda parte do minicurso, aconteceu uma tempestade com muitos relâmpagos em Amargosa. A ocorrência do fenômeno na cidade, pouco antes da discussão do conteúdo com a turma, parece ter contribuído para manter e aumentar ainda mais a curiosidade dos alunos acerca dos conceitos anteriormente apresentados, gerando bastante discussão sobre o que eles tinham visto durante a tempestade. Essa discussão evidenciou que o grande número de respostas negativas na questão 8 do préteste não condizia com o que observamos, pois uma quantidade maior de alunos descreveram situações presenciadas em outras tempestades ocorridas na cidade.

Usando exemplos simples, conseguimos trazer outros questionamentos dos alunos, como aconteceu quando explicamos o comportamento dielétrico do ar em condições normais:

P2: Eu estou perto dessa tomada e não tomei nenhum choque, porque o ar é isolante elétrico. Agora pergunto a vocês: se o ar é isolante, por que o raio consegue "atravessá-lo"?

A3: Por causa da chuva!

P2: Você lembra-se do vídeo que passamos na primeira aula? Caiu um raio numa árvore mesmo sem chuva! Então, não é bem por esse caminho! Vamos lá, pessoal, quem mais arrisca?

A8: Por causa da eletricidade?

A4: Porque ele é neutro?

P2: Quando há um acúmulo muito intenso de cargas na nuvem, isso vai gerar uma intensa indução na terra. Chamamos esse fenômeno de diferença de potencial. Uma enorme diferença de potencial "quebra" momentaneamente as propriedades isolantes do ar; então, o ar torna-se condutor de eletricidade e o raio consegue "atravessá-lo". É importante frisarmos que isso não acontece em situações normais. Em baixas diferenças de potencial, o ar é isolante elétrico.

Alguns estudantes desconheciam a existência de raios ascendentes, aqueles que acontecem da terra para a nuvem, o que também foi identificado no questionário. Podemos atribuir esse "desconhecimento" ao fato dos raios ascendentes serem um fenômeno de difícil visualização e que provavelmente são pouco comentados nos noticiários da televisão, pois, tirando as concepções espontâneas e as influências culturais, notamos a televisão como sendo um dos meios de informação mais predominantes com que os estudantes tinham acesso a informações sobre assuntos relacionados à eletricidade atmosférica em geral. 
Além do conteúdo sobre o fenômeno dos raios, na segunda parte da intervenção tivemos a preocupação de apresentar para os alunos as formas de prevenção contra descargas elétricas, o que manteve a fidelidade do nosso minicurso com seu título.

Destacamos um questionamento feito por um aluno, quando explicamos as formas de prevenção de acidentes com raios:

A14: Tenho uma dúvida: a melhor solução se uma pessoa estiver num local sem abrigo durante uma trovoada, é se deitar no chão até a tempestade passar? Pois os raios são atraídos por pontos altos, não é?

P1: Sim, os raios incidem com maior frequência em pontos altos. Mas, a descarga elétrica do raio também se conduz pelo solo com facilidade. Então, se a pessoa estiver deitada, maior parte do seu corpo estará em contato com o solo e então o choque elétrico será muito mais intenso. A melhor solução é agachar-se e pôr a cabeça entre os joelhos. Fazendo isso, seu único contato com o chão será os pés e também, você será um ponto mais baixo.

Quando explicamos o processo de formação de um relâmpago numa nuvem, nenhum dos alunos se manifestou. É importante destacarmos que ainda não existe um consenso sobre a origem dos relâmpagos, pois dentro da própria comunidade científica existem dezenas de teorias concorrentes tentando explicar a formação das nuvens que provocam as tempestades (MEDEIROS, A.; MEDEIROS, C., 2002).

Ao fim do minicurso, mostramos aos alunos uma maneira de estimar a distância de uma tempestade a partir do intervalo de tempo de observação do relâmpago e do trovão, com a utilização de um dos trechos do vídeo apresentado na primeira aula. Assim, encerramos o minicurso, tendo atingindo os objetivos de dar subsídios mínimos para o entendimento de alguns fenômenos elétricos atmosféricos, formas de prevenção durante as tempestades, e de fazer o levantamento das concepções espontâneas dos alunos.

\section{Considerações finais}

Notamos uma carência muito grande de trabalhos que analisem e discutam concepções espontâneas sobre fenômenos associados aos raios. Isso evidencia a importância desse tipo de pesquisa para o ensino de ciências naturais.

Por meio das investigações realizadas com o intuito da obtenção e análise das concepções espontâneas dos alunos sobre raios, podemos notar que muitas destas concepções são oriundas de superstições populares, como o ato de cobrir espelhos durante as tempestades.

Embora sempre esteja presente nos noticiários da televisão, o assunto "raios" parece ser apresentado de forma superficial, com explicações muito simples, o que não ajuda na desconstrução de determinadas concepções espontâneas, levando em consideração que esse assunto aparentemente desperta bastante interesse por parte das pessoas em geral, tanto pelo medo quanto pelo fascínio, como foi verificado através do nível de participação dos estudantes do minicurso. 
Debater tais concepções pode não ser uma tarefa tão trivial quanto parece. No entanto, tais temas podem estar mais presentes na sala de aula, através dos conteúdos de física. Por isso, o minicurso “Como não ser atingido por raios?”, além da investigação e análise das concepções espontâneas, se mostrou importante no sentido de alertar sobre os riscos provenientes das tempestades, e também por apresentar maneiras cientificamente corretas para se proteger durante o acontecimento desse fenômeno incrível, porém devastador.

Por fim, podemos concluir que a aplicação de uma proposta didática estruturada a partir da metodologia empregada, o levantamento e a análise das concepções espontâneas, contribuem para a investigação das crenças e/ou mitos sobre os fenômenos naturais, trazendo novas perspectivas para o ensino de ciências naturais.

\section{Referências}

ASSIS, A. K. T. Os Fundamentos Experimentais e Históricos da Eletricidade. Montreal: Apeiron, 2010. Disponível em: <http://www.ifi.unicamp.br/ assis/Eletricidade.pdf>. Acesso em: 15 abr. 2016.

BAHIA. Governo do Estado. Secretaria de Cultura. IPAC. Festa de Santa Bárbara. Salvador: Fundação Pedro Calmon, 2010.

CERQUEIRA JR., W.; CERQUEIRA, G. L. Ensino de Física a partir da realidade dos alunos. Revista Extensão, v. 1, 9. ed, p. 55-64, 2015. Disponível em: <https://www2.ufrb.edu.br/revistaextensao/index.php/component/content/article/23>. Acesso em: 19 abr. 2016.

DELIZOICOV, D. Ensino de física e a concepção freiriana da educação. Revista de Ensino de Física, v. 5, n. 2, 1983. Disponível em: <http://www.sbfisica.org.br/rbef/pdf/vol05a19.pdf>. Acesso em: 3 ago. 2015.

DELIZOICOV, D.; ANGOTTI, J. A. P. Física. 2. ed. São Paulo: Cortez, 1992.

ELAT - Grupo de Eletricidade Atmosférica - Instituto Nacional de Pesquisas Espaciais (INPE). Eletricidade Atmosférica - Como começaram os estudos sobre eletricidade atmosférica? Disponível em: <http://www.inpe.br/webelat/homepage/menu/relamp/eletricidade.atmosferica/historia.php>. Acesso em: 3 ago. 2015a.

Relâmpagos - Definição. Disponível em: <http://www.inpe.br/webelat/homepage/menu/relamp/relampagos/definicao.php>. Acesso: 25 jul. 2015 b.

Mitos e Lendas. Disponível em: <http://www.inpe.br/webelat/homepage/menu/el.atm/mitos.php>. Acesso em: 8 jun. 2015c.

. Perguntas e respostas. Disponível em: <http://www.inpe.br/webelat/homepage/menu/el.atm/perguntas.e.respostas.php>. Acesso em: 25 jul. 2015 d. 
Informações - Ranking de municípios. Disponível em: <http://www.inpe.br/webelat/docs/Ranking_BR.pdf>. Acesso em: 5 ago. 2015e.

FEITOSA, S. M. R. Alterações climáticas em Teresina- PI decorrentes da urbanização e supressão de áreas verdes. 2010. Dissertação (Mestrado) - Universidade Federal do Piauí, Programa de Pós-Graduação em Desenvolvimento e Meio Ambiente. Disponível em: $<$ http://www.ufpi.br/subsiteFiles/mestambiente/arquivos/files/TEXTUAIS\%20Cd_17\%20ABRIL\%20PDF_3.pdf>. Acesso em: 04 ago. 2015.

FERRARI, P. C. Temas contemporâneos na formação docente a distância: uma introdução à teoria do caos. 2008. Tese (Doutorado). Universidade Federal de Santa Catarina, Programa de Pós-Graduação em Educação Científica e Tecnológica. Disponível em: <https://repositorio.ufsc.br/bitstream/handle/123456789/91442/256624.pdf?sequence=1>. Acesso em: 04 ago. 2015.

GASPAR, A. Compreendendo a física: eletromagnetismo e física moderna. 2. ed. São Paulo: Ática, 2013.

HALLIDAY, D.; RESNICK, R.; WALKER, J. Fundamentos da Física: Eletromagnetismo. 8. ed. Rio de Janeiro: LTC, 2009. v. III.

HOLTON, G.; RUTHERFORD, F. J.; WATSON, F. G. Projecto Física: Unidade 4 Luz e Eletromagnetismo - Texto e manual de experiências e actividades. Lisboa: Fundação Calouste Gulbenkian, 1978.

MEDEIROS, A.; MEDEIROS, C. Os raios no imaginário popular. Revista Brasileira de Investigação em Educação em Ciências, v. 2, n. 3 p. 84-96, 2002. Disponível em: <http://revistas.if.usp.br/rbpec/article/download/168/153>. Acesso em: 25 jul. 2015.

MENDES JR., O.; DOMINGUES, M. O. Introdução à Eletrodinâmica Atmosférica. Revista Brasileira de Ensino de Física, v. 24 n. 1, p. 3-19, 2002. Disponível em: <http://www.scielo.br/pdf/rbef/v24n1/a02v24n1.pdf>. Acesso em: 25 jul. 2015.

MUENCHEN, C. A disseminação dos três momentos pedagógicos [tese]: um estudo sobre práticas docentes na região de Santa Maria/RS. 2009. Tese (Doutorado em Educação Científica e Tecnológica) - Universidade Federal de Santa Catarina, Florianópolis.

MUENCHEN, C.; DELIZOICOV, D. Concepções sobre problematização na educação em ciências. In: CONGRESSO INTERNACIONAL SOBRE INVESTIGACIÓN EM DIDÁTICA DE LAS CIENCIAS, 9, 2013. Disponível em: <http://congres.manners.es/congres_ciencia/gestio/creacioCD/cd/articulos/art_297.pdf>. Acesso em: 26 jul. 2015.

NUSSENZVEIG, H. M. Curso de Física Básica: Eletromagnetismo. Mecânica. 4. ed. São Paulo: Edgard Blucher, 2002. v. 3 
PINTO JR., O. A arte da guerra contra os raios. São Paulo: Oficina de Textos, 2005.

POUZADOUX, C. Contos e lendas da mitologia grega. São Paulo: Companhia das Letras, 2001. 264p.

SABA, M. M. F. A Física das Tempestades e dos Raios: Questões e dúvidas frequentes. A Física na Escola, v. 2, n. 1, 2001. Disponível em:

<www.sbfisica.org.br/fne/Vol2/Num1/raios.pdf>. Acesso em: 25 jul. 2015.

YOUNG, H. D.; FREEDMAN, R. A. Física III: Eletromagnetismo. 12. ed. São Paulo: Addison Wesley, 2009. 